\title{
ESPIRITUALIDADE EM CUIDADOS PALIATIVOS: UMA REVISÃO SISTEMÁTICA COM METANÁLISE
}

\author{
João Ygor de Oliveiral ${ }^{1}$ Modesto Leite Rolim Neto ${ }^{2}$
}

Introdução: Um tema repleto de discussão e opiniões como a espiritualidade, principalmente quando relacionado a oncologia merece a devida atenção diante evidências que mostram sua inserção na prática clínica. O debate atual sublinha que a depressão e a ansiedade são duas condições clínicas que são relatadas como melhoradas após intervenções espirituais na ambiência da oncologia, particularmente na inserção dos cuidados paliativos. Objetivo: Caracterizar as evidências relevantes no determinar os efeitos da espiritualidade e/ou religião na depressão e ansiedade em pacientes oncológicos em final de vida, extraindo os resultados mais uteis em torno dos principais fatores de intervenção em cuidados paliativos. Método: Foram utilizados os seguintes bancos de dados: Pubmed, Scopus, Web of Science, PsycINFO e The Cochrane Collaboration. Com o intuito de tornar a busca mais segura e tornar maior a reprodutibilidade, resolveu-se filtrar os dados através da combinação de descritores com uso dos operados booleanos AND e OR. Ao todo foram encontradas 717 referências (248 PubMED, 192 Cochrane, 9 PsycINFO, 2 Web of Science e 266 Scopus). Com a posterior aplicação dos critérios de inclusão e exclusão 12 estudos foram inseridos na amostra (n). Para análise estatística foi empregado o Programa Review Manager versão 5.3 (Cochrane Collaboration). Resultados: Tanto na depressão como na ansiedade houve um favorecimento dos grupos experimentais em cuidados paliativos com significância de $\mathrm{p}=0,0006$ para a depressão e $\mathrm{p}=0,004$ para a ansiedade. A significativa heterogeneidade verificada nas duas análises é referente às diferentes terapias e contextos em que são aplicadas na ambiência oncológica. Conclusão: Os estudos sublinham que a religiosidade/espiritualidade pode atenuar a atividade do sistema nervoso simpático e aumentar a ativação parasimpática. Estudos recentes refletem que a religiosidade/espiritualidade também tem sido relacionada a níveis mais baixos de cortisol circulante ou à responsividade do cortisol e, portanto, podem contribuir para a redução das queixas somáticas. Neste enquadre situacional, intervenções espirituais trazem consequências positivas no campo dos cuidados paliativos em pacientes em final de vida, principalmente na melhora de parâmetros de depressão e ansiedade com favorecimento significativo para os grupos experimentais $\mathrm{p}=0,0006$ para a depressão e $\mathrm{p}=0,004$ para a ansiedade.

Palavras-chave: Cuidados Paliativos; Oncologia; Religiosidade; Espiritualidade; Depressão; Ansiedade.

\footnotetext{
${ }^{1}$ Acadêmico de Enfermagem, Faculdade de Juazeiro do Norte - FJN

${ }^{2}$ Estácio/Faculdade de Medicina de Juazeiro do Norte - FMJ

Autor Correspondente: ygorjoao57@gmail.com.

28 Id on Line Rev. Mult. Psic. V.12, N. 40. 2018 - ISSN 1981-1179 EDIÇÃO ESPECIAL: I CURSO DE ONCOLOGIA DO CARIRI / II JORNADA DE PESQUISA QUANTI-QUALITATIVA EM ONCOLOGIA. JUAZEIRO DO NORTE, 05 A 10 DE MARÇO DE 2018. Edição eletrônica em http://idonline.emnuvens.com.br/id
} 